\title{
Long-term follow-up in PMM2-CDG: are we ready to start treatment trials?
}

\author{
Peter Witters, MD, $\mathrm{PhD}^{1,2}$, Tomas Honzik, MD, $\mathrm{PhD}^{3}$, Eric Bauchart, PhD ${ }^{4}$, Ruqaiah Altassan, MD ${ }^{5,6,7}$, \\ Tiffany Pascreau, PharmD ${ }^{8,9}$, Arnaud Bruneel, PharmD, PhD ${ }^{10,11}$, \\ Sandrine Vuillaumier, PharmD, $\mathrm{PhD}^{10}$, Nathalie Seta, $\mathrm{PhD}^{10,12}$, Delphine Borgel, PharmD, $\mathrm{PhD}^{8,9}$, \\ Gert Matthijs, $\mathrm{PhD}^{13}$, Jaak Jaeken, MD, PhD ${ }^{1,2}$, Wouter Meersseman, MD, PhD ${ }^{14,15}$, \\ David Cassiman, MD, $\mathrm{PhD}^{16}$, Lonlay Pascale de, MD, $\mathrm{PhD}^{4}$ and Eva Morava, MD, PhD ${ }^{1,17}$
}

Purpose: PMM2-CDG is the most common congenital disorder of glycosylation (CDG), which presents with either a neurologic or multisystem phenotype. Little is known about the longitudinal evolution.

Methods: We performed data analysis on PMM2-CDG patients' clinical features according to the Nijmegen CDG severity score and laboratory data. Seventy-five patients ( 28 males) were followed up from $11.0 \pm 6.91$ years for an average of $7.4 \pm 4.5$ years.

Results: On a group level, there was no significant evolution in overall clinical severity. There was some improvement in mobility and communication, liver and endocrine function, and strabismus and eye movements. Educational achievement and thyroid function worsened in some patients. Overall, the current clinical function, the system-specific involvement, and the current clinical assessment remained unchanged.On follow-up there was improvement of biochemical variables with (near) normalization of activated partial thromboplastin time (aPTT), factor XI, protein $\mathrm{C}$, antithrombin, thyroid stimulating hormone, and liver transaminases.

Conclusion: PMM2-CDG patients show a spontaneous biochemical improvement and stable clinical course based on the Nijmegen CDG severity score. This information is crucial for the definition of endpoints in clinical trials.

Genetics in Medicine (2019) 21:1181-1188; https://doi.org/10.1038/s41436018-0301-4

Keywords: PMM2-CDG; CDG severity scale; long-term followup; coagulation; liver function test

\section{INTRODUCTION}

Congenital disorders of glycosylation (CDG) are a family of diseases. The common denominator is that they all affect the most important posttranslational modification of proteins and lipids: glycosylation. ${ }^{1}$ CDG were initially described by Jaak Jaeken and currently comprise a group of some 135 distinct genetic entities. ${ }^{1}$ The most abundant type is PMM2CDG (initially called CDG-1a, or phosphomannomutase 2 deficiency). This subtype affects $\mathrm{N}$-linked protein glycosylation, and leads to either a primarily neurological condition, or to a multisystem disease. So far more than 900 patients have been reported with PMM2-CDG, with varying disease severity. The infantile neurovisceral form is associated with hepatogastrointestinal disease (failure to thrive, protein losing enteropathy, liver disease), cardiac disease (e.g., pericardial fluid collection, cardiomyopathy), renal disease, and laboratory alterations including abnormal endocrine function and coagulopathy. ${ }^{2}$ PMM2-CDG can be lethal, but if patients reach the age of 3-4 years, CDG follows a more stable course, or may reportedly even improve. ${ }^{3}$ The neurological type is characterized by psychomotor disability, hypotonia, muscle weakness, cerebellar ataxia, strabismus, retinitis pigmentosa, spasticity, dystonia, and neuropathy.

The most characteristic clinical signs in PMM2-CDG are the abnormal fat distribution on the buttocks (fat pads) and inverted nipples. Screening is usually performed by serum

\footnotetext{
${ }^{1}$ Pediatrics and Metabolic Center, University Hospitals Leuven, Leuven, Belgium; ${ }^{2}$ Department of Development and Regeneration, Faculty of Medicine, KU Leuven, Leuven, Belgium; ${ }^{3}$ Department of Pediatrics, First Faculty of Medicine, Charles University and General University Hospital, Prague, Czech Republic; ${ }^{4}$ AP-HP, Necker University Hospital, French National Reference Centre for Inborn Errors of Metabolism, Paris, France; ${ }^{5}$ Medical Genetic Department, Montréal Children Hospital, McGill University, Montreal, Canada; ${ }^{6}$ Department of Pediatrics, University Hospitals Leuven, Leuven, Belgium; ${ }^{7}$ Department of Medical Genetics, King Faisal Specialist and Research Hospital, Riyadh, Saudi Arabia; ${ }^{8}$ AP-HP, Hôpital Necker, Service d'Hématologie Biologique, Paris, France; ${ }^{9}$ UMR_S1176, INSERM, Univ. Paris-Sud, Université Paris-Saclay, Le Kremlin-Bicêtre, France; ${ }^{10}$ Biochemistry Department, AP-HP, Bichat Hospital, Paris, France; ${ }^{11}$ UMR INSERM 1193, Faculty of Pharmacy, Paris-Sud University, Paris, France; ${ }^{12}$ Biochemistry Department, Paris Descartes University, Bichat Hospital, Paris, France; ${ }^{13}$ Center for Human Genetics, KU Leuven, Leuven, Belgium; ${ }^{14}$ Metabolic Center, University Hospitals Leuven, Leuven, Belgium; ${ }^{15}$ Department of General Internal Medicine, Faculty of Medicine, KU Leuven, Leuven, Belgium; ${ }^{16}$ Gastroenterology-Hepatology and Metabolic Center, University Hospitals Leuven, Leuven, Belgium; ${ }^{17}$ Department of Clinical Genomics, Mayo Clinic, Rochester, MN, USA. Correspondence: Peter Witters (peter.witters@uzleuven.be)
} 
sialotransferrin isoelectric focusing/capillary electrophoresis, or by mass spectrometry, which typically display a so-called type 1 pattern (decreased tetrasialo- and increased di- and asialo-transferrin).

Currently, there is no effective treatment for PMM2-CDG. In the past, trials with oral or intravenous mannose did not show any clinical benefit, ${ }^{4,5}$ in spite of the clear biochemical improvement in vitro in patients' fibroblasts. ${ }^{4,6}$ Upcoming clinical trials aim at chaperone therapy, liposomal or chemically camouflaged mannose-1-phosphate supplementation, antisense therapy using morpholino oligonucleotides, or inhibition of connecting pathways, as possible therapeutic approaches. ${ }^{7}$

Little is known about the long-term follow-up of CDG patients. Due to highly variable clinical manifestations and laboratory abnormalities, and even intrapersonal variability of laboratory results, it is not easy to make predictions on the outcome or natural history of an individual patient, or to define relevant endpoints for clinical trials. Quite recently natural history studies were initiated (clinicaltrials.gov identifier NCT03173300) to prepare for upcoming clinical trials.

As there is no formal guideline for follow-up of PMM2CDG patients, data on patients are collected sporadically, and not well-structured. The purpose of the current study is to describe the long-term follow-up of a large cohort of CDG patients with emphasis on laboratory data and a validated clinical score, the CDG progression score. ${ }^{8}$

\section{Patient selection}

\section{MATERIALS AND METHODS}

Through the EURO-CDG network, we collected patients from centers with larger PMM2-CDG patient populations. Patients were included from the Reference Center for Inherited Metabolic Disease, AP-HP, Necker-Enfants Malades Hospital, IMAGINE Institute affiliate, University Paris DescartesSorbonne Paris Cité, Paris, France; the Department of Pediatrics, First Faculty of Medicine, Charles University and General University Hospital, Prague, Czech Republic; and the Department of Pediatrics and Metabolic Center, University Hospitals Leuven, Leuven, Belgium. All patients had genetically confirmed PMM2-CDG.

\section{Retrospective data collection}

Current work was approved by the local ethics committee at University Hospitals Leuven, Leuven, Belgium. Data was collected in Excel files on demographic and biometric variables (age, gender, height, weight, head circumference). Information was retrieved on biochemical variables such as coagulation (international normalized ratio [INR], activated partial thromboplastin time (aPTT), factor IX, factor XI, antithrombin, protein $\mathrm{C}$, protein $\mathrm{S}$ ); hormones (insulin-like growth factor [IGF], IGF binding protein 3 [IGFBP3], thyroid stimulating hormone $[\mathrm{TSH}]$, free thyroxine [T4], adrenocorticotropic hormone $[\mathrm{ACTH}]$, cortisol, follicle-stimulating hormone $[\mathrm{FSH}]$, luteinizing hormone $[\mathrm{LH}])$, glucose; cholesterol; high-density lipoprotein; triglycerides; aspartate and alanine transaminases (AST and ALT); creatine kinase; and lactate dehydrogenase.

The clinical characteristics and disease progression score of the patients were documented and followed by the Nijmegen CDG rating scale ${ }^{8}$ (Online supplement 1 ). Age-appropriate scales were used at different evaluation time points. This score collects information on (1) current function over the last 4 weeks (based on an interview with the patient or caregiver regarding vision, hearing, communication, feeding, mobility); (2) system-specific involvement (history in the last 6 months on seizures, encephalopathy, bleeding diathesis or coagulation defect; and gastrointestinal, endocrine, respiratory, cardiovascular, renal, liver function, and blood anomalies); and (3) current clinical assessment as per clinical examination (growth, development, vision, strabismus, and eye movement; myopathy, ataxia, pyramidal and extrapyramidal symptoms, and neuropathy). Higher scores are associated with worse clinical state. ${ }^{8}$ Treatments with medication like anticoagulation therapy or supplementation with levothyroxine were recorded.

\section{Statistics}

SPSS 22 for windows (SPSS Inc., Chicago, IL, USA) and R version 3.4.3 were used for statistical analysis. All results were expressed as means \pm standard deviation. For differences between repeated measurements in the same individual the Wilcoxon signed rank test was used. Correlations were performed using the Pearson correlation, double sided. A $p$ value $<0.05$ was considered statistically significant. Graphs were constructed using $\mathrm{R}$.

A sample size of 34 patients was calculated to achieve a power of $80 \%$ and a level of significance of $5 \%$ (two-sided) for detecting a medium effect size of 0.5 between paired observations (http://statulator.com).

Due to the retrospective nature of this study, observations in patients with incomplete data were treated as not available for that specific graph, or descriptive or statistical analysis (pairwise exclusion). Every effort was made to collect a complete data set, including contacting local referring hospitals.

\section{Patient cohort}

\section{RESULTS}

We collected data on 75 patients with a mean age of $11.02 \pm$ 6.91 years. There were 28 male and 47 female patients, most likely a chance finding as no difference is to be expected. On 61 patients longitudinal follow-up data were available. They were followed up for $7.4 \pm 4.5$ years. Overall, there were 268 observations (mean of 2.85 observations per patient [range 1-9]). One patient died during the follow-up due to multiorgan failure and invasive aspergillosis at the age of 11.8 years.

There were two patients with homozygous pathogenic variants $(\mathrm{L} 32 \mathrm{R} / \mathrm{L} 32 \mathrm{R}$ and, T231M/T231M; the remainder of the patients had compound heterozygous pathogenic 
a

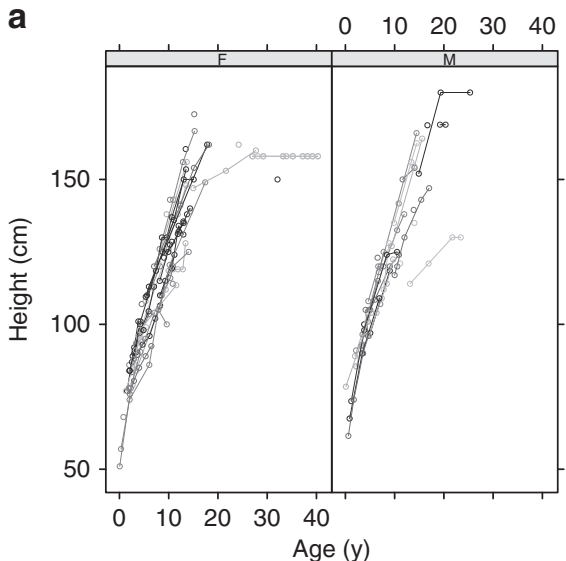

d

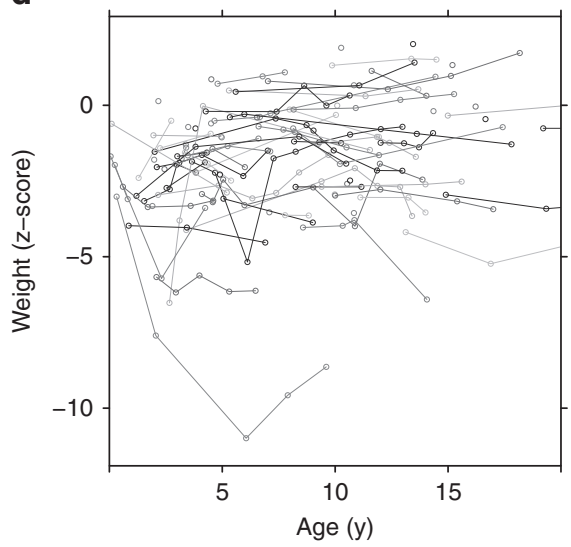

b

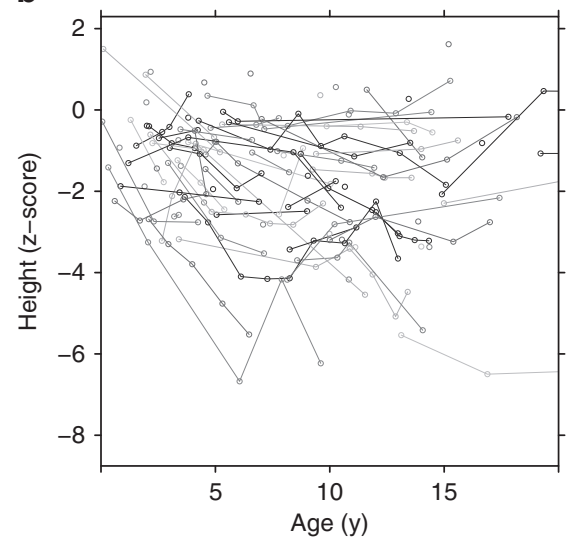

e

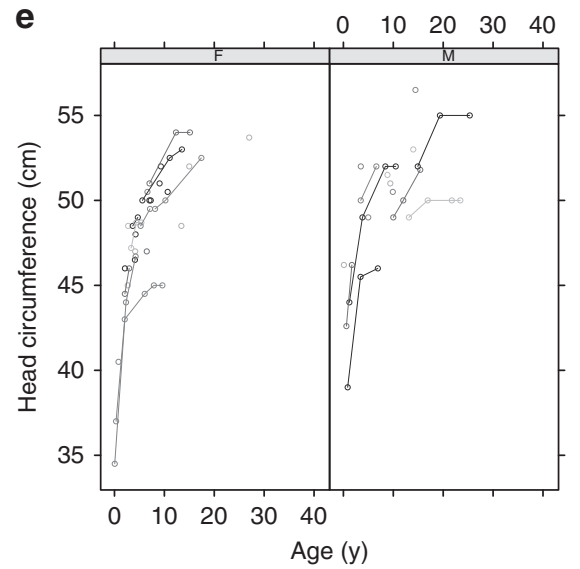

C

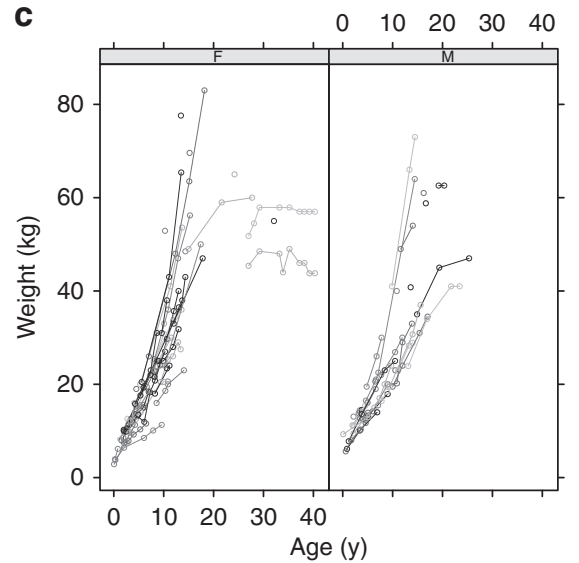

f

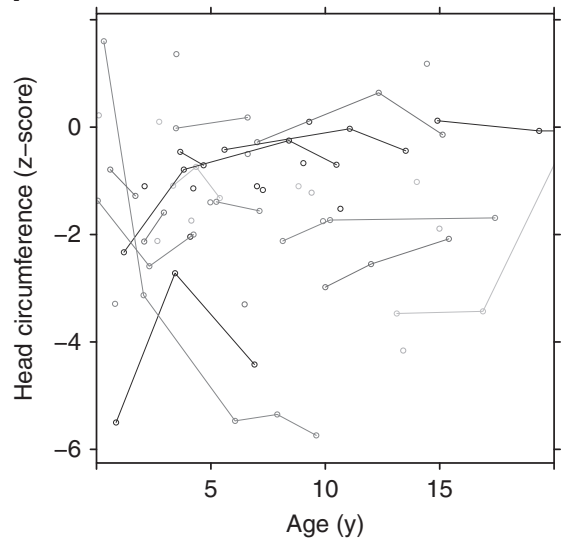

Fig. 1 Biometric charts: growth curves of PMM2-CDG patients. (a) Growth curve (cm for age) by gender. (b) Growth z-score. (c) Weight curve (kg for age) by gender. (d) Weight $z$-score. (e) Head circumference curve (cm for age) by gender. (f) Head circumference $z$-score. All data points represent individual measurements. Data collected from the same individual is connected by lines.

variants). The most frequently encountered pathogenic variants were R419H $(n=45)$, P113L (14), F119L (10), E139K (9), C241S (7), and T237M (6). The most common compound heterozygous pathogenic variant was $\mathrm{P} 113 \mathrm{~L} /$ $\mathrm{R} 419 \mathrm{H}(n=9)$.

Patients who had feeding problems, gastrointestinal comorbidity, bleeding diathesis, coagulation abnormalities, anemia or cytopenia, endocrine abnormalities, respiratory issues, or cardiovascular, liver, renal problems, or growth delay, as evidenced by the Nijmegen CDG severity score, were considered to have a multisystem disease (i.e., neurovisceral form) and not the isolated neurological form of PMM2-CDG. Using this definition there were $68(90.7 \%)$ patients with the neurovisceral form and 7 patients (9.3\%) with the isolated neurological form. Moreover, there were 9 additional patients (12\%) with the neurovisceral form that at some point during their follow-up had only neurological symptoms. This was due to the appearance $(n=3)$, disappearance $(n=4)$, or both $(n=$ 2 ) of multisystem features such as renal, endocrine, and liver findings; cytopenia, coagulation disorders, or growth issues.

The patients with the neurologic form all had strabismus and global developmental delay (with continued developmental progress in 6/7) and most had ataxia (6/7). A seizure disorder was present in $4 / 7$.
During the follow-up (totaling 449 patient years), there were 11 stroke-like episodes in 5 patients ( 1 per 70.8 years). Interestingly, there was 1 patient with 5 stroke-like episodes and 2 patients with 2 stroke-like episodes each. All these patients had the neurovisceral type of PMM2-CDG. They had normal prothrombin time, aPTT but decreased levels of factor IX, XI, and antithrombin (AT). Interestingly, 3 of these stroke-like episodes did also occur in adults (ages 21, 21, and 24 years).

There was a clear delay in growth (height $\mathrm{z}$-score $-1.21 \pm$ 1.48), weight (weight $z$-score $-1.62 \pm 1.71$ ) and head circumference $(-1.10 \pm 1.58)$. During follow-up there was no significant improvement in these findings. In fact, there was no catch-up growth but rather a deterioration to $-2.02 \pm$ 1.83, $p<0.001$ (see Fig. 1). There were no significant biometric differences (expressed as $z$-scores) between males and females.

\section{Clinical evolution assessed by the CDG severity score}

The initial values for the Nijmegen CDG severity score are shown in Table 1 . The CDG severity score can be found in the online supplement 1 .

Regarding the current clinical function over the preceding 4 weeks (subscore 1 , see online supplement 1 ), the median 
Table 1 Distribution of initial scores in \%

\begin{tabular}{|c|c|c|c|c|}
\hline Current clinical function & 0 & 1 & 2 & 3 \\
\hline Vision $(n=68)$ & 47.1 & 36.8 & 11.8 & 4.4 \\
\hline Hearing $(n=71)$ & 88.7 & 7.0 & 2.8 & 1.4 \\
\hline Communication $(n=73)$ & 27.4 & 32.9 & 20.5 & 19.2 \\
\hline Feeding $(n=72)$ & 65.3 & 25.0 & 5.6 & 4.2 \\
\hline Self-care $(n=67)$ & 20.4 & 26.9 & 14.9 & 37.3 \\
\hline Mobility $(n=73)$ & 5.5 & 11.0 & 23.3 & 60.3 \\
\hline Educational achievements $(n=70)$ & 5.7 & 24.3 & 32.9 & 37.1 \\
\hline System-specific involvement & 0 & 1 & 2 & 3 \\
\hline Seizures $(n=75)$ & 80.0 & 17.3 & 1.3 & 1.3 \\
\hline Encephalopathy $(n=74)$ & 94.6 & 1.4 & 1.4 & 2.7 \\
\hline $\begin{array}{l}\text { Bleeding diathesis or coagulation defects } \\
(n=70)\end{array}$ & 48.6 & 49.3 & 2.9 & 4.3 \\
\hline Gastrointestinal $(n=73)$ & 69.9 & 26.0 & 1.4 & 2.7 \\
\hline Endocrine $(n=70)$ & 58.6 & 22.9 & 18.6 & 0 \\
\hline Respiratory $(n=72)$ & 100.0 & 0 & 0 & 0 \\
\hline Cardiovascular $(n=74)$ & 89.2 & 4.1 & 5.4 & 1.4 \\
\hline Renal $(n=68)$ & 81.3 & 9.3 & 0 & 0 \\
\hline Liver $(n=72)$ & 58.3 & 40.3 & 1.4 & 0 \\
\hline Blood $(n=70)$ & 82.9 & 15.7 & 0 & 1.4 \\
\hline Current clinical assessment & 0 & 1 & 2 & 3 \\
\hline Growth $(n=71)$ & 33.8 & 54.9 & 4.2 & 7.0 \\
\hline Development $(n=68)$ & 1.5 & 0 & 3.0 & 0 \\
\hline Vision $(n=64)$ & 50.0 & 31.1 & 14.1 & 4.7 \\
\hline Strabismus and eye movement $(n=73)$ & 6.8 & 54.8 & 37 & 1.4 \\
\hline Myopathy $(n=68)$ & 85.3 & 5.9 & 7.4 & 1.9 \\
\hline Ataxia $(n=73)$ & 2.7 & 21.9 & 35.6 & 39.7 \\
\hline Pyramidal $(n=65)$ & 81.5 & 16.9 & 0 & 1.5 \\
\hline Extrapyramidal $(n=64)$ & 95.3 & 4.7 & 0 & 0 \\
\hline Neuropathy $(n=70)$ & 44.3 & 51.4 & 2.9 & 1.4 \\
\hline
\end{tabular}

Distribution of the scores according to the Nijmegen CDG severity score. Each item is scored from 0 to 3 according to the current clinical function (based on patient and/or caregiver interview over the preceding 4 weeks), system-specific involvement (based on patient and/or caregiver interview and clinician's knowledge of the patient and clinical notes over the preceding 6 months), and the current clinical assessment (based on the clinical examination at the time of visit). Development is scored from 0 to 6

A score of 0 indicates age-appropriate findings. The higher the score the more abnormal. For instance for vision the scoring is as follows $(0=$ Normal: no parental/patient concerns;

$1=$ Mild: inattention to small objects in visual field or parent concerned about abnormality of visual behavior; $2=$ Moderate: visual impairment not fully corrected with glasses or inattention to large objects in visual field; $3=$ Severe: not recognizing faces or registered blind or using additional visual aids. The complete scoring detail can be found in the online supplement 1.

patient had mild visual problems (such as inattention to small objects), normal hearing, impaired verbal communication, normal feeding, moderate self-care issues (requiring help with all age-appropriate tasks), severely impaired mobility (being wheelchair/carrier dependent), and moderately severe education achievement issues (attending special school or nursery) (see Table 1). The mean total of all elements of subscore 1 was $8.63 \pm 3.99$ on a maximum of 21 (a higher score indicates a worse clinical state, $n=71$ ). During follow-up the vision, hearing, feeding and self-care showed neither improvement nor deterioration $(p=N S)$. (see spaghetti plots in online supplement 2). There was a decrease in score, indicating clinical improvement, in communication over time (from $1.32 \pm 1.08$ to $1.26 \pm 1.03, \mathrm{p}=0.027$, amelioration toward intelligible verbal communication) and mobility (from $2.38 \pm$ 0.89 to $2.28 \pm 0.92, p=0.007$, evolution towards mobility, albeit age-inappropriate). Interestingly, three patients evolved from wheelchair dependency to ambulation with only difficulty in climbing stairs or walking uphill. There was an increase in educational score, indicating evolution from attending special school toward not attending school primarily due to illness (from $2.01 \pm 0.93$ to $2.22 \pm 0.81, p=0.002$ ).

Overall, the current function (subscore 1) did not change over time (8.77 \pm 4.22 at the end of follow-up, $p=0.45)$ (see Fig. 2).

Regarding the system-specific involvement over the last 6 months (subscore 2, see online supplement 1) the most often encountered issues were bleeding diathesis or coagulation defects, mainly as laboratory abnormalities, without a need for therapy. Other frequently encountered abnormalities were mild constipation or unexplained vomiting or diarrhea $(<1$ week) and mildly impaired liver function tests, without evidence of hepatic failure (see Table 1). On follow-up the latter appeared to improve (score evolving from $0.43 \pm 0.53$ to $0.31 \pm 0.5, p=0.033$ ). All the other findings remained stable, except for a slight deterioration in endocrine score (from 0.60 \pm 0.79 to $0.82 \pm 0.833, p=0.033$ ). There were no significant changes in the total subscore 2 over time (from $2.73 \pm 2.52$ to $3.29 \pm 2.89, p=0.44$, NS) (see Fig. 2).

Regarding the current clinical assessment (subscore 3, see online supplement 1) the average patient had a mildly impaired growth (height or weight less than the 2nd centile but growing parallel to it), impaired development (global developmental disability with continued developmental progress), normal or mildly affected vision, intermittent strabismus, ptosis or impaired eye movement at extremities, no clinical neuropathy, moderate ataxia (gait abnormality requiring assistance or severe upper limb dysmetria, no pyramidal or extrapyramidal signs, with mild neuropathy [only areflexia]) (see Table 1). The mean scores were $11.17 \pm$ 3.60 out of a maximum of 31 . On follow-up there was slight improvement of the strabismus and eye movements (score from $1.33 \pm 0.63$ to $1.21 \pm 0.71, p=0.046$ ). All the other items remained stable. Overall there were no significant changes of the subscore over time (at the end of follow-up 11.48 \pm 3.70 , $p=0.707$, NS) (see Fig. 2).

Combination of the different subscores gives a total maximal score of 82 . The mean score at the start was $22.27 \pm 9.09$. The lowest score was 7 , the highest score 50 . This score remained surprisingly stable over time (score at the end 23.52 \pm 9.44 , $p=0.64$, NS). There was no evidence for global improvement or significant deterioration in the current cohort.

The maximal scores obtained in our cohort at any time were $16 / 21$ in section I, 9/30 in section II, and 18/31 in section III. There was just one patient who ever scored positive for respiratory involvement. For every element of the score there were patients who scored the minimum (0), demonstrating the variability of disease presentation (see Fig. 2). 

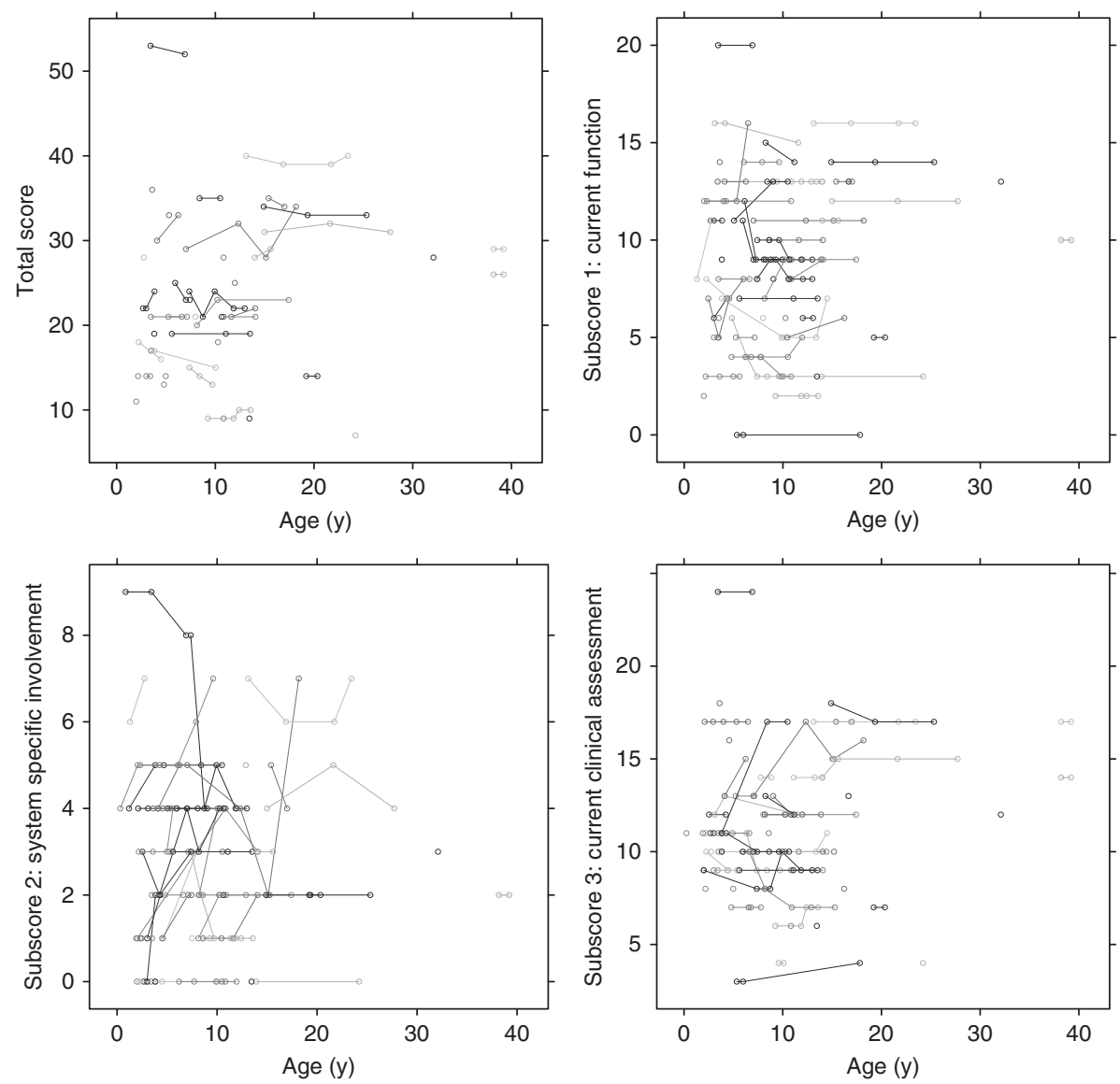

Fig. 2 Congenital disorders of glycosylation (CDG) severity scores. Spaghetti plots of Nijmegen CDG severity score according to age showing the (a) a total score, (b) subscore 1 (current function), (c) subscore 2 (system specific involvement) and (d) subscore 3 (current clinical assessment). Every point represents one observation. Observations in the same patient are connected by lines.

The detailed age-related evolution of individual elements of the score in individual patients can be seen in online supplement 2 .

\section{Evolution of biochemical characteristics}

The biochemical characteristics of the patients can be found in Table 2.

Coagulation abnormalities were the most striking. Patients had on average, abnormal coagulation studies demonstrated by prolongation of aPTT (38.1 s [normal values: $25.1-36.5 \mathrm{~s}$ ]), and decreased levels of factor XI (43.5\% [70-130\%]). Also anticoagulation was disturbed with decreased levels of antithrombin (51.5\% [80-130\%]) and protein C (59.7\% $[60-150 \%])$. On follow-up there was a normalization of the aPTT (34.4 s) and protein C (67.1\%) in most patients. Factor $\mathrm{XI}$ also improved significantly (55.6\%) and there was a trend toward improvement of antithrombin (59.6\%).

Liver tests (AST and ALT) also improved significantly over time. In infancy/childhood, transaminases were frequently elevated several-fold (AST 84.9 IU/L [<37 IU/L], ALT 98/78 IU/L $(<40 \mathrm{IU} / \mathrm{L}])$. However, on follow-up they nearly normalized (see Fig. 3). Creatine kinase was only intermittently elevated. Cholesterol (total and high-density lipoprotein $[\mathrm{HDL}]$ ) and triglycerides were usually (low)-normal.
Cholesterol significantly increased over time but remained in the normal range. Hypoglycemia was surprisingly common in some patients, mostly in prepubertal age (13 patients, $17 \%$ ). However, at the group level, glycemia was not significantly low. Missing data for lactate dehydrogenase (LDH), copper, and ceruloplasmin precluded comprehensive analysis.

TSH was often elevated in childhood (13 patients, $17 \%$ ). However, on follow-up this significantly improved in 4 patients ( 1 treated, 3 untreated by elthyroxine). T4 levels were mostly normal. Fifteen patients were on T4 supplements at some stage during follow-up. In 6 patients this was started at the age of $1,1,1,13,15$, and 15 years. In only two patients, supplements were stopped at the age of 14 and 20 years old.

IGF shows an age-related increase as can be expected. Due to paucity of data we cannot comment on IGFBP3 levels and ACTH. LH and FSH showed puberty-related changes.

The spaghetti plots on the individual patients for all the above-mentioned variable can be found in online supplement 3.

\section{Correlations between clinical data and biochemistry}

There was a significant correlation between the CDG severity score (total score) and numerous coagulation variables such as factor XI $(\mathrm{R}=-0.581, p<0.001, n=48)$, antithrombin 
Table 2 Biochemical measurements at the initial inclusion and at the end of follow-up

\begin{tabular}{|c|c|c|c|}
\hline $\begin{array}{l}\text { Variable (nl } \\
\text { values) }\end{array}$ & $\begin{array}{l}\text { Inclusion } \\
\text { (mean } \pm \text { stdev. } \\
{[n] \text { ) }}\end{array}$ & $\begin{array}{l}\text { End of follow-up } \\
\text { (mean } \pm \text { stdev. }[n])\end{array}$ & $p$ value \\
\hline INR (0.8-1.2) & $1.07 \pm 0.90(37)$ & $1.05 \pm 0.09(40)$ & 0.538 \\
\hline $\begin{array}{l}\text { aPTT } \\
(25.1-36.5 \mathrm{~s})\end{array}$ & $\begin{array}{l}38.09 \pm 27.40 \\
(50)\end{array}$ & $34.39 \pm 8.31(44)$ & ${ }^{\mathrm{a}} 0.013$ \\
\hline $\begin{array}{l}\text { Factor IX } \\
(70-130 \%)\end{array}$ & $72.05 \pm 1.00(37)$ & $82.84 \pm 23.11(40)$ & 0.153 \\
\hline $\begin{array}{l}\text { Factor XI } \\
(70-130 \%)\end{array}$ & $43.45 \pm 1.00(39)$ & $55.63 \pm 32.50(42)$ & ${ }^{\mathrm{a}} 0.022$ \\
\hline $\begin{array}{l}\text { Antithrombin III } \\
(80-130 \%)\end{array}$ & $51.52 \pm 1.00(46)$ & $59.47 \pm 26.50$ & 0.053 \\
\hline $\begin{array}{l}\text { Protein C } \\
(60-150 \%)\end{array}$ & $59.65 \pm 1.00(45)$ & $67.07 \pm 25.26$ & ${ }^{\mathrm{a}} 0.037$ \\
\hline $\begin{array}{l}\text { Protein S } \\
(60-150 \%)\end{array}$ & $\begin{array}{l}71.62 \pm 30.00 \\
(42)\end{array}$ & $71.95 \pm 19.66(40)$ & 0.549 \\
\hline AST (<37 IU/L) & $\begin{array}{l}84.78 \pm 12.00 \\
(52)\end{array}$ & $39.15 \pm 19.09(46)$ & ${ }^{a}<0.001$ \\
\hline $\operatorname{ALT}(<40 \mathrm{IU} / \mathrm{L})$ & $98.78 \pm 5.88(50)$ & $40.57 \pm 30.27(46)$ & ${ }^{a}<0.001$ \\
\hline $\begin{array}{l}\text { Creatinine } \\
\text { kinase (<180 IU/ } \\
\text { L) }\end{array}$ & $\begin{array}{l}130.75 \pm 19.00 \\
(27)\end{array}$ & $122.10 \pm 60.96(29)$ & 0.224 \\
\hline $\begin{array}{l}\text { Triglycerides } \\
(<1.69 \mu \mathrm{M})\end{array}$ & $0.76 \pm 0.25$ & $0.71 \pm 0.44$ & 0.936 \\
\hline $\begin{array}{l}\text { Total } \\
\text { cholesterol } \\
(<4.92 \mu \mathrm{M})\end{array}$ & $3.31 \pm 1.19(40)$ & $3.46 \pm 0.71(38)$ & ${ }^{\mathrm{a}} 0.005$ \\
\hline $\begin{array}{l}\text { HDL cholesterol } \\
(>1.16 \mu \mathrm{M})\end{array}$ & $1.43 \pm 0.64(11)$ & $1.55 \pm 0.37(16)$ & 0.446 \\
\hline $\begin{array}{l}\text { Glucose } \\
(3.9-6.1 \mu \mathrm{M})\end{array}$ & $4.56 \pm 1.00(40)$ & $4.71 \pm 1.03(36)$ & 0.116 \\
\hline $\begin{array}{l}\text { TSH }(0.27-4.20 \\
\mathrm{mIU} / \mathrm{L})\end{array}$ & $2.70 \pm 0.02(54)$ & $2.32 \pm 1.29(41)$ & ${ }^{\mathrm{a}} 0.003$ \\
\hline $\begin{array}{l}\mathrm{T} 4(5.1-14.1 \\
\mu \mathrm{g} / \mathrm{dL})\end{array}$ & $12.46 \pm 1.00$ & $12.70 \pm 3.13(41)$ & 0.550 \\
\hline $\begin{array}{l}\text { IGF1 (age- } \\
\text { dependent, } \mu \mathrm{g} / \\
\text { L) }\end{array}$ & $\begin{array}{l}166.80 \pm 7.00 \\
(24)\end{array}$ & $173.99 \pm 104.45$ & 0.088 \\
\hline $\begin{array}{l}\text { ACTH (10-60 } \\
n g / L)\end{array}$ & $24.26 \pm 10.80(8)$ & $33.06 \pm 26.67(5)$ & 0.593 \\
\hline $\begin{array}{l}\text { Cortisol } \\
(2.8-496 \mathrm{mM})\end{array}$ & $\begin{array}{l}163.57 \pm 2.00 \\
(28)\end{array}$ & $174.84 \pm 133.48$ & 0.148 \\
\hline $\begin{array}{l}\mathrm{LH}(2.4-95 / 6 \mathrm{IU} / \\
\mathrm{L})\end{array}$ & $12.15 \pm 0.00(19)$ & $22.66 \pm 13.86(19)$ & 0.182 \\
\hline $\begin{array}{l}\text { FSH }(1.2-134.8 \\
\mathrm{IU} / \mathrm{L})\end{array}$ & $46.04 \pm 1.10(19)$ & $81.19 \pm 42.90(20)$ & 0.064 \\
\hline
\end{tabular}

$(\mathrm{R}=-0.516, p<0.001, n=55)$, protein $\mathrm{C}(\mathrm{R}=-0.478, p<$ $0.001, n=55)$. No other significant correlations were found.

\section{DISCUSSION}

Information on the natural history of PMM2-CDG is virtually absent from the literature. With the exception of case reports or small series, this is the first article documenting clinical follow-up in a standardized fashion by using the validated Nijmegen CDG severity score, which has low interobserver variability. ${ }^{8}$

We showed that over a period of more than 7 years, there is indeed very little change in the clinical condition. There is no real progression or improvement of the disease as a whole. However, there are improvements in communication, mobility, liver disease, strabismus, or eye movements while other disease aspects deteriorate such as educational achievements and endocrine abnormalities. These findings balance out so that the total CDG severity score and even the three subscores (i.e., the current function, system specific involvement, and current clinical assessment) remain unchanged over time.

This stable clinical state can only be interrupted by strokelike episodes. These were described in $7 \%$ of patients. However, even after suffering a stroke-like episode, there were no significant changes in CDG severity score. In contradiction to previous publications, there were also adult patients suffering from these stroke-like episodes (oldest at 24 years in current series). Mortality in PMM2-CDG has been described in the multisystem (neurovisceral) form and occurs mainly before the age of 4 years. ${ }^{3}$ In our mainly older cohort, there was only one demise on follow-up, due to multiorgan failure. This indicates a favorable vital prognosis.

Regarding the biochemistry, we do see several variables improving over time. To our knowledge, there has been only one very small follow-up study on biochemical values in 25 patients. ${ }^{2}$ In our cohort, we see the most striking changes in serum transaminases and coagulation/anticoagulation abnormalities.

With regard to liver involvement, hepatomegaly is the most frequent clinical finding. ' Biochemically, this has been associated with elevated transaminases in a high proportion of patients $(12.5-100 \%)$ (refs. ${ }^{2,10-13}$ ) more often than in the neurological form. ${ }^{2}$ Usually, the transaminases become more elevated during viral infections. In our series, there was a several-fold elevation of transaminases that normalized mainly before the 2nd decade. This is consistent with the findings reported in a smaller cohort. ${ }^{2}$ Liver ultrasound can demonstrate steatosis. ${ }^{14-16}$ Liver biopsies have rarely been performed. They mostly show liver steatosis ${ }^{17-19}$ and lysosomal inclusions in the hepatocytes. ${ }^{20}$ The mechanism for the development of liver steatosis remains unknown.

Coagulation disorders and thrombosis are real concerns in PMM2-CDG. These might require specific measures in case 

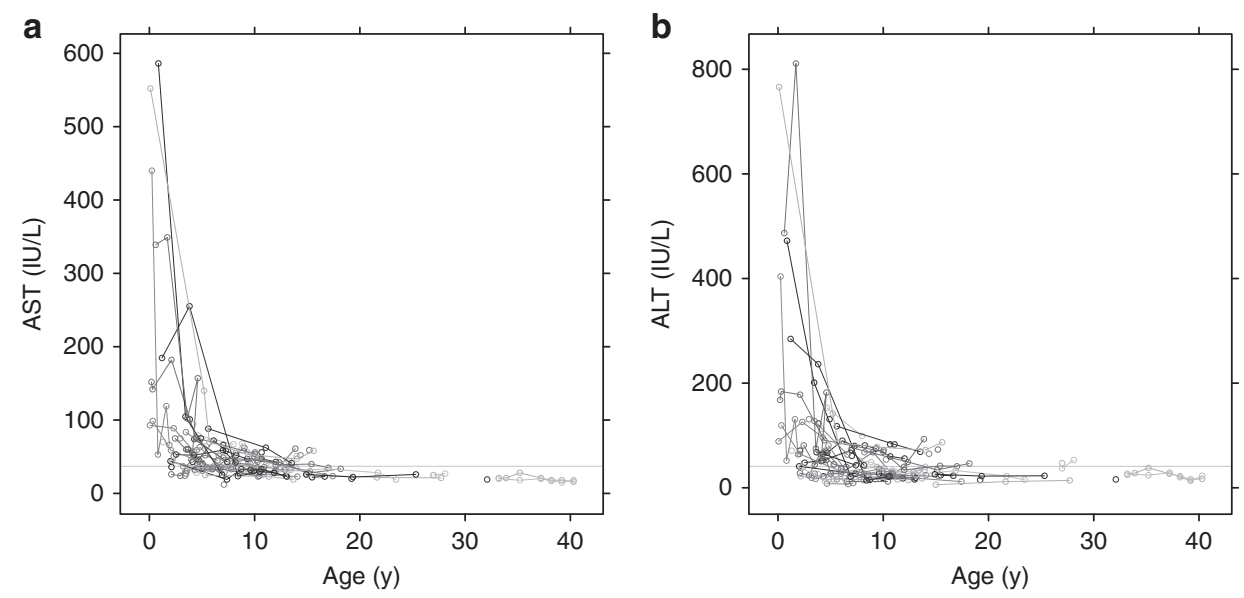

Fig. 3 Spaghetti plots of liver tests. (a) Aspartate transaminase (AST) and (b) alanine transaminase (ALT). Every point represents one observation. Observations in the same patient are connected by lines. The gray line represents the upper limit of normal.

of surgery (plasma transfusion for coagulation disorders) or when recovering from surgery (early mobilization and adequate hydration to minimize risk for deep venous thrombosis or abnormal clotting). Coagulation abnormalities have been described in 344 PMM2-CDG patients so far. Both procoagulant and anticoagulant factors are affected. Antithrombin deficiency was the most reported (160 patients) followed closely by factor XI and protein C deficiency (128 and 123 patients respectively). Protein S and factor IX can also be decreased ( 40 and 17 patients respectively). We show for the first time that there is a gradual normalization of aPTT, protein $\mathrm{C}$, and a clear improvement in antithrombin levels, and confirm the previously reported improvement in factor XI. ${ }^{2}$ This implies that the risk in adults could be less than expected, however, parents and caregivers should be educated on symptoms of thrombosis so they can be treated quickly and appropriately. Careful follow-up of coagulation and laboratory variables over several years is hence informative.

Failure to thrive in the first year of life is a commonly reported feature (141 individuals with PMM2-CDG). It is mostly associated with other extraneurological symptoms. ${ }^{2,10,15,16,18,19}$ In our series, there are decreased mean $z$ scores for weight, height, and head circumference. Surprisingly, there is no catch-up growth as is normally seen. It is unclear whether this is a primary problem, or due to insufficient caloric intake. Maybe aggressive nutritional support early in life (circumventing issues with hypotonia and oral muscle dysfunction) could make a difference.

In the clinical follow-up of PMM2-CDG patients with the neurological type, one has to remain vigilant for the appearance of other multisystemic features. We have shown that $12 \%(9 / 75)$ can evolve over time from a neurological form to the multisystem form or vice versa. Most like these are not clearly delineated entities. Because of this overlap, PMM2-CDG could present a clinical spectrum from asymptomatic over isolated neurological involvement to hydrops fetalis. $^{21}$
Overall our study adds two new insights in PMM2-CDG. First, clinicians making a new diagnosis of PMM2-CDG, or following up patients with PMM2-CDG, can counsel the parents that a stable clinical state can be expected in the age range we studied ( 1 month to 40 years). They can also be reassured that a lot of the biochemical abnormalities, more specifically the coagulation and liver tests, will ameliorate if current findings can be replicated in a prospective natural history study.

Second, for the upcoming therapy trials in PMM2-CDG, it is paramount to take into account the clinical condition of patients, because on follow-up we see a spontaneous improvement of biochemical variables. Therefore, future nutritional therapeutic trials will ideally be double blind randomized controlled trials.

\section{ELECTRONIC SUPPLEMENTARY MATERIAL}

The online version of this article (https://doi.org/10.1038/s41436018-0301-4) contains supplementary material, which is available to authorized users.

\section{ACKNOWLEDGEMENTS}

P.W. is supported by the clinical research fund, University Hospitals Leuven, Leuven, Belgium. E.M. and D.C. are recipients of the clinical investigatorship, FWO Flanders, Belgium. T.H. is supported by the Ministry of Health of the Czech Republic: MZ AZV 16-31932A and the grant RVO-VFN 64165. This work was supported by the European Reference Network for Rare Hereditary Metabolic Disorders (MetabERN) and by a grant from ANR-15RAR3-0004-06 under the frame of ERARE-3, the ERA-Net for Research on Rare Diseases.

\section{DISCLOSURE}

The authors declare no conflicts of interest. 


\section{REFERENCES}

1. Jaeken J, Peanne R. What is new in CDG? J Inherit Metab Dis. 2017:40:569-586

2. Schiff $M$, Roda $C$, Monin ML, et al. Clinical, laboratory and molecular findings and long-term follow-up data in 96 French patients with PMM2CDG (phosphomannomutase 2-congenital disorder of glycosylation) and review of the literature. J Med Genet. 2017;54:843-851.

3. Funke S, Gardeitchik T, Kouwenberg D, et al. Perinatal and early infantile symptoms in congenital disorders of glycosylation. Am J Med Genet A. 2013;161A:578-584.

4. Kjaergaard S, Kristiansson B, Stibler $H$, et al. Failure of short-term mannose therapy of patients with carbohydrate-deficient glycoprotein syndrome type 1A. Acta Paediatr. 1998;87:884-888.

5. Mayatepek E, Kohlmuller D. Mannose supplementation in carbohydratedeficient glycoprotein syndrome type I and phosphomannomutase deficiency. Eur J Pediatr. 1998;157:605-606.

6. Panneerselvam K, Freeze $\mathrm{HH}$. Mannose corrects altered N-glycosylation in carbohydrate-deficient glycoprotein syndrome fibroblasts. J Clin Invest. 1996;97:1478-1487.

7. Brasil S, Pascoal C, Francisco R, et al. CDG Therapies: from bench to bedside. Int J Mol Sci. 2018;19.

8. Achouitar S, Mohamed M, Gardeitchik T, et al. Nijmegen paediatric CDG rating scale: a novel tool to assess disease progression. J Inherit Metab Dis. 2011;34:923-927.

9. Marques-da-Silva D, Dos Reis Ferreira V, Monticelli M, et al. Liver involvement in congenital disorders of glycosylation (CDG). A systematic review of the literature. J Inherit Metab Dis. 2017;40:195-207.

10. Kjaergaard S, Schwartz M, Skovby F. Congenital disorder of glycosylation type la (CDG-la): phenotypic spectrum of the R141H/F119L genotype. Arch Dis Child. 2001;85:236-239.

11. Grunewald S, Schollen E, Van Schaftingen E, Jaeken J, Matthijs G. High residual activity of PMM2 in patients' fibroblasts: possible pitfall in the diagnosis of CDG-la (phosphomannomutase deficiency). Am J Hum Genet. 2001;68:347-354
12. Arnoux JB, Boddaert N, Valayannopoulos $\mathrm{V}$, et al. Risk assessment of acute vascular events in congenital disorder of glycosylation type la. Mol Genet Metab. 2008;93:444-449.

13. Monin ML, Mignot C, De Lonlay $P$, et al. 29 French adult patients with PMM2-congenital disorder of glycosylation: outcome of the classical pediatric phenotype and depiction of a late-onset phenotype. Orphanet J Rare Dis. 2014;9:207.

14. Al Teneiji A, Bruun TU, Sidky S, et al. Phenotypic and genotypic spectrum of congenital disorders of glycosylation type I and type II. Mol Genet Metab. 2017;120:235-242.

15. de Lonlay $P$, Seta $N$, Barrot $S$, et al. A broad spectrum of clinical presentations in congenital disorders of glycosylation I: a series of 26 cases. J Med Genet. 2001;38:14-19.

16. Barone R, Sturiale L, Sofia V, et al. Clinical phenotype correlates to glycoprotein phenotype in a sib pair with CDG-la. Am J Med Genet A. 2008;146A:2103-2108.

17. Enns GM, Steiner RD, Buist $N$, et al. Clinical and molecular features of congenital disorder of glycosylation in patients with type 1 sialotransferrin pattern and diverse ethnic origins. J Pediatr. 2002;141: 695-700.

18. Damen $G$, de Klerk $H$, Huijmans J, den Hollander J, Sinaasappel M. Gastrointestinal and other clinical manifestations in 17 children with congenital disorders of glycosylation type la, Ib, and Ic. J Pediatr Gastroenterol Nutr. 2004;38:282-287.

19. Perez-Duenas B, Garcia-Cazorla A, Pineda M, et al. Long-term evolution of eight Spanish patients with CDG type la: typical and atypical manifestations. Eur J Paediatr Neurol. 2009;13:444-451.

20. Grunewald S, De Vos R, Jaeken J. Abnormal lysosomal inclusions in liver hepatocytes but not in fibroblasts in congenital disorders of glycosylation (CDG). J Inherit Metab Dis. 2003;26:49-54.

21. Vuillaumier-Barrot S, Isidor B, Dupre T, Le Bizec C, David A, Seta N. Expanding the spectrum of PMM2-CDG phenotype. JIMD Rep. 2012;5: 123-125. 